XXIII.

\title{
THIRD YEAR OBSERVATIONS OF CLINICAL OZENA AND ITS VACCINE TREATMENT.
}

BY

Henry Horn, M. D., and Ernst Albrecht Victors, M. D.,

\author{
San Francisco.
}

INTRODLCTION.

In the past year our investrgations relative to fetid ozena have been chiefly clinical. Our work has been considerably enhanced by virtue of the prize award of the Pacific Coast Oto-Ophthalmological Society, whereby we were enabled to procure suitable cageings for the animals used in these studies. We have enjoyed, also, the cooperation of many rhinologists throughout the country, and take this means of thanking them for the submission of material for bacteriologic study, for clinical data of cases under observation, and for many valuable suggestions pertaining to our work. In order to acquire a broader expression of the clinical aspects of atrophic rhinitis, and to determine what general value has been attained through vaccine therapy in this condition, a comprehensive questionare has been submitted to all interested in this subject.

In our previous bacteriologic studies we were impressed by the striking resemblance of the coccobacillus fetidus ozenæ of Perez to B. bronchosepticus, the specific organism of canine distemper. To facilitate the bacteriologic nomenclature we had deemed it advisable to group the coccobacillus of Perez. with B. bronchosepticus, and proposed its designation as B. rhinosepticus as a more fitting appellation. This change in name we have followed in our recent contributions upon this subject.

It was our purpose to limit our investigations along certain specific lines and to determine: 
(1) The existence of different types of ozena upon a bacteriologic basis, and to establish the relationship of atrophic rhinitis to accessory sinus disease.

(2) The clinical relationship of $B$. rhinosepticus and the B. Friedlander group to ozena.

(3) The value of specific vaccine therapy in the various types of atrophic rhinitis.

We have tabulated these results, and note a considerable degree of similarity in expressions of the clinical aspects of ozena as well as results attained through vaccine administration. The brevity of questionare answers cannot fully allow individual expression, and we are therefore incorporating in this report such personal communications as are pertinent and more illuminating to the subject in hand.

\section{CLINICAL DIFFFRENTIATION OF TYPFS.}

It is apparent that the inclination to group all the types of atrophic rhinitis with crusting and odor as fetid ozena, and to consider them from the same etiologic viewpoint, or apply to them the same therapeutic measures, is obviously incorrect. In our previous communication on this subject we laid stress upon accessory sinus involvement as complicating fetid atrophic rhinitis, and presented such bacteriologic studies to demonstrate the constant presence of $\mathrm{B}$. rhinosepticus or some type of the B. mucosus capsulatus group in all cases of fetid atrophic rhinitis. We are convinced that in these cases the accessory sinuses are too frequently disregarded, and that turbinal atrophy is at times a secondary process. Mechanical intranasal distortion, allowing accumulation and organization of secretions, might create a favorable environment for bacterial lodgment, especially for the Friedlander organisms. Permanent escape of the accessory sinuses from infection from a chronically infected contiguous membrane seems hardly possible. In more than fifty per cent of cases of fetid atrophic rhinitis under study was there definite accessory sinus involvement, especially of the sphenoidal and ethmoidal cells. Whatever the nasal pathology may be, its importance seems distinctly subordinate to the condition of the contributal nasal chambers, and demands a different consideration from fetid atrophic rhinitis simplex. 
Whilst a certain conflict of bacterial entities, namely, B. rhinosepticus and the Friedlander group organisms, still prevails in culture findings, the constant presence of one of these types in all cases of true atrophic rhinitis (fetidus) lends encouragement to the establishment of a bacterial causc.

There is still a third group, presenting some odor, a thickened dirty mucoid secretion rather than crusting, and turbinate hypertrophy rather than atrophy. Sinus involvement may or may not coexist. The organism rhinosepticus is never recovered from these cases, although the Friedlander bacillus is not infrequently isolated in luxuriance. There appears to be neither clinical nor bacteriologic foundation for grouping such cases with fetid atrophic rhinitides.

CI,INICAL RELATIONSHIP OF IB, RHINOSEP'TICUS ANI) 3. FRIEDLANDER GROLY' TO OZFNA.

In our previous communication on this subject we were inclined to ascribe, from the bacteriologic viewpoint, to $B$. rhinosepticus the sole etiologic roble in clinical ozena. B. Friedlander was looked upon as a secondary invader. Although the coisolation of B. rhinosepticus was noted in a few instances of Friedlander cases, the latter organism seemed destined to dominate the entire bacterial stage-an end-reaction of immutual symbiosis. 'There have arisen as yet no impressions to indicate a recession from such assumption. The final solution of this problem, however, must rest upon bacteriologic experimentation. These have not as yet been sufficiently advanced to warrant definite conclusions.

Certain clinical results, also, tend to emphasize the etiologic importance of B. rhinosepticus, in that improvement usually occurs in cases of fetid ozena from which both organisms are isolated, under rhinosepticus vaccine treatment, but no results have ever been obtained with even an autogenous Friedlander vaccine. Even frank Friedlander infection cases at times respond gratifyingly to rhinosepticus vaccine, although the marked failures and most discouraging results have always been in cases of seemingly pure B. Friedlander infection with extensive accessory sinus disease. Again, in a considerable number of instances, initially giving plate colonies of B. Friedlander and absence of B. rhinosepticus, the rhinosepticus or- 
ganism was isolated after several injections of this vaccine. We offer in explanation of this occurrence the theory of focal activation of a deeper or higher seat of infection.

Reference has been made to the common existence of Friedlander bacilli in rhinitis when associated with accessory sinus involvement. This organism of ten appears to persist in pure culture under such conditions. We are, though, mindful of the probable prior sinus invasion by rhinosepticus, or that secretions are mechanically arrested through atrophy and enlargement of the nasal chambers, creating an ultimate Friedlander habitat.

Perșistent absence of $B$. rhinosepticus findings in nonfetid atrophic rhinitis, chronic hypertrophic rhinitis, sinuitis without odor and normal individuals, is one of the strongest arguments presenting itself in determining the etiologic relationship of this organism. In the past year a consistent endeavor has been made in determining, from a clinical standpoint, whether or not this organism might be but a simple saprophytic entity. Bacteriologic findings have been uniformly negative. Of interest also is the paucity of bacteria noted in nonfetid nasal affections and in the nasal cavities of normal individuals.

We have as yet pursued no definite lines of investigation in determining the modus and means of infection. We are, though, inclined to support the original contention of Perez, in that the disease is acquired from dogs. This hypothesis is apparently negatived in the clinical charts herewith presented; nevertheless, we feel that the question of animal pets has been too closely answered in that through the general domestication of the dog a much more liberal contact has been indulged in. An interesting case in point of contact and possible bacterial communication has come to our attention. A mother and child presented themselves with definite clinical ozena. On interrogation it was found that a pet dog was afflicted with a chronic nasal catarrh, which condition preceded that of the humans. Bacteriologic examinations revealed a I3. rhinosepticus infection in the mother and child, and a 13. bronchosepticus infection in the dog-apparently a distemper carrier. We are as yet compelled to reserve comment upon these findings.

We do not find the isolation of $B$. rhinosepticus encumbered 
with any difficulties, and are becoming more and more rigid in our demand for the demonstration of this organism in sustaining the diagnosis of true ozena. During the year, three hundred and forty-three specimens were submitted for bacteriologic study. These cases embrace the entire gamut of intrarhinal pathology as well as a certain group of individuals with normal nasal mucous membranes. Of this number the cultures from one hundred and twenty-six cases showed B. rhinosepticus-all clinically true ozenas-and seventy-six cases, a portion of which were apparently true ozena, gave exclusive B. Friedlander cultures. Of twenty-two of the B. rhinosepticus culture cases were cultures mixed with B. Friedlander. $B$. pyocyaneus was present in four instances. The presence of this organism makes the isolation of other organisms difficult and often impossible. One hundred and thirtyseven cases were negative to either $B$. rhinosepticus or $B$. Friedlander, and were often sterile.

\section{TABLE I.}

BACTERIOLOGIC SLMMARY OF NASAL, SECRETIONS EXAMINED DURING THE PAST YEAR, INCLUDING CASES OF TRUE ATROPHIC RHINITIS, NONATROPHIC RHINITIS, AND NORMAI, INDIVIDUALS.

B. Rhinosepticus :

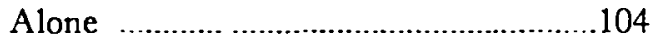

With B. Friedlander ............................. 22

Total 126

B. Friedlander :

Alone .

With rhinosepticus.

Total

B. pyocyaneus.

Negative to B. rhinosepticus, or B. Friedlander, or sterile cases. 
VACCINE THERAPY.

We deem it a far cry to attempt to establish the etiologic relationship of a microorganism to a certain disease through clinical results obtained by injections of suspensions of the killed organism in question. The fundamental purport of our investigation has been one of etiology. On the other hand, whilst appreciating the caution necessary in attempting to establish the causal relationship of a certain microorganism to a definite morbid process, we have inclined to vaccine therapy in the hope of finding some more potent weapon of combat against this obnoxious disease, to strengthen our heretofore limited and unpromising measures of relief.

Whether or not the rhinosepticus vaccine is specific, or through the parenteral digestion of a foreign protein the colloidal dispersion renders a mobilization of ferments, thereby elevating the titre of infection resistance, is a moot point in biology still to be determined. We are dealing with a focal infection, distinctly insidious and chronic. Intravenous vaccine injections have produced a transient leucocytosis and constitutional reaction, without in any way influencing the intranasal conditions. Subcutaneous injections have, on the contrary, afforded us promise of amelioration of the manifestations of a heretofore hopeless condition. Clinical improvement is the common response. Clinical cures have been rare in that relapse after discontinuance of treatment is not infrequent. Bacteriologic cures, except in one or two instances, have never been obtained. Ample drainage in conjunction with vaccine administration appears to be the most fruitful method of treatment, where there is accessory sinus involvement.

Incident to a scattered and dissociated therapeutic investigation, and with an aim at uniformity, a certain empiricism must of necessity obtain. In supplying a vaccine quite generally throughout the country for the treatment of ozena, we have prescribed such outlines of administration, in reference to dosage and injection interim, as were suggested by our own experience. We have advised as an initial injection about $200,000,000$ killed organisms, increasing this and subsequent doses by $200,000,000$ every fourth day. Such dose first preceding that inductive of constitutional reaction is termed the 
dose of tolerance. This usually occurs between the administration of the $600,000,000$ to $1,000,000,000$ dose. The interim of injection is now lengthened to seven days and the doses increased about 250,000,000.

In the main, the treatment of our own cases has followed this outline. We have found it necessary, though, to exercise a considerable watchfulness of the patients' individual variation in regard to idiosyncrasy, susceptibility and toleration. Some patients seem unable to tolerate small doses of vaccine, but after a persistent endeavor take relatively large doses without discomfort. Some show no improvement through this method of therapy until excessively large doses are reached, whilst we have noted an occasional patient respond clinically only to small doses and with marked and discomforting nasal manifestations on large doses. In other words, it is our impression that the vaccine treatment of ozena parallels that of most other insidious and relatively benign infections. We have not as yet a suitable measure or index of immologic response other than our clinical sense. The vaccine therapy of ozena is encumbered, and the negative results encountered, like unto the chronic infections in general.

\section{ABSTRACT OF CASE REPORTS.}

The response to a questionare submitted by us to those having used the vaccine prepared by us during the past year were on the whole very satisfactory. About thirty-five records were filled out with sufficient detail upon which reliable conclusions could be based.

It would appear from these answers that ozena is a widespread disease, prevalent in all parts of the United States, afflicting rich and poor, children and the middle aged, those in urban and rural communities, and showing no choice or disregard to occupation and vocation. Nor'does it appear that the disease has a predilection for those living in a questionable hygienic environment.

From various sources we gather the impression that many cases of ozena have been neglected owing to unpromising measures for relief at disposal, and that the ozena patient was rather 
looked upon as an unwelcome visitor. Latterly there appears to be a distinct revival of interest in this subject, as well as a keener appreciation of the importance of associant accessory sinus involvement. Liberally discounting our own zeal in advancing a vaccine for the treatment of these cases and the general enthusiasm engendered by any new therapeutic measure, it nevertheless appears that the results of treatment by means of vaccine have been on the whole satisfactory and in some instances brilliant.

A general survey of the clinical comments of other observers and their vaccine results check remarkably well with our own experience. Clinical cures have been claimed with reservation and many relapses have been noted. In Table II are shown the end-results of vaccine treatment of cases reported by us in our previous communication. We have had opportunity of studying twenty-six additional cases, and these are charted in Table III. In Table IV are shown the reports of clinical aspects of ozena as noted by other observers, with comments on vaccine therapy.

Briefly summarizing the salient features of clinical ozena, we may conclude as follows:

FamiLY History.-There is an apparent negation to the claim of the frequent infection of other members of the same family.

In FECTION From ANIMALS.-As charted, it appears that the possibility of infection from lower animals, especially dogs, is decidedly remote. We feel, however, that too strict an interpretation of animal contact and animal pets has been indulged in that the domestication of the dog is a most common custom in this country. We feel that, upon a bacteriologic basis at any rate, the original contention of Perez will ultimately be proven to be the truth.

Odor Detected by Patients.-The previously held belief that patients with ozena of long standing ultimately lose the ability of detecting their own odor is apparently incorrect.

Cifaracteristrc OdoR.-The odor from the ozena patient is so variously described that it appears impossible to correctly qualify it. We have at times been inclined to note an odor as "not characteristic" and be supported by negative bacteriologic findings. On the other hand, the organism of Perez 
has been isolated when no odor whatsoever existed. The inclination is to ascribe the odor, both in character and degree, to the extent of atrophy and possibilities of drainage, rather than to the products of the activities of the causal microorganism.

Characteristic Crusts.-There are no characteristic crusts in ozena. The type depends upon the age, extent of the process, and the mechanics of the intranasal condition. In the very old, highly atrophic cases, the flaky white crusts simply represent the normal condition for a given amount of atrophy.

ATROPHY.-In old cases atrophy is almost invariably bilateral. We have, however, every reason to believe that a unilateral ozena can exist.

ACCESSORY SInUSEs.-In eighty-five per cent of our cases was involvement of the accessory sinus more than probable. This point has been discussed elsewhere in this paper. We think it highly probable that in every case the sinuses are invaded by the offending organism, and no form of treatment can be considered which does not give proper weight to this fact. The frontals, because of the difficulty of examination, we know nothing about; the other sinuses seem about equally involved.

Clinical Probabilities Beffort Bacteriologic ExaminaTION.-It would seem that there is a certain clinical complex characteristic of bacillus rhinosepticus ozena. In our twenty-six cases, judged before the bacteriologic study, only three mistakes were made as to the true bacteriologic nature of the complaint. This would seem to indicate that the ozena due to bacillus rhinosepticus and Friedlander group are clinical entities, and should be classed as such in contradistinction to marked atrophic rhinitis with odor and crusts due to syphilis, tuberculosis, and other constitutional diseases.

VACCINE INJECTION.-The average number of injections used ranges around fifteen. The improvement was usually noted by the fourth injection, and continued up to the twelfth or fifteenth. From then on it seems to settle itself down into a long process of supplying the patient with enough antibodies to keep the disease well under control, and in some cases can be continued indefinitely with good results. 
Character of Reaction.-With proper vaccines, given in proper doses, the reaction is never severe. Marked symptoms are to be avoided. The best results are obtained where one remains just under the reaction point. The seven day interval, after the proper dose has been reached, seems to be the most convenient and most useful.

Results.-Although our main interest in the study of ozena during the last three years has been largely confined to the question of etiology and clinical pathology, general interest seems to be in the results. The beneficial result of vaccine treatment was marked in the great majority of cases. End results or the permanency of clinical cure have been difficult to establish, owing to the fact that certain cases were lost from observation when crusting and odor disappeared, Thus in twenty-three cases treated in Chart II of our last year's report, thirteen noted as clinical cures did not return for treatment.

Summary of 1916 Results, Still Under Observation.Case 1, the priest, who was obliged to douche his nose every few hours in order to carry on his confessional work, has had no return of symptoms as far as crusting and headaches, but from time to time notices a slight odor, easily controlled by an occasional douche.

Case 2 remains a clinical cure, without crusts and odor, and never has to douche the nose. The $B$, rhinosepticus can always be demonstrated.

Case 3, one of the most evil smelling of this series, remains clinically cured without any local treatment. This person could not be admitted to the reception room on account of the foulness of odor.

Cases 10, 11 and 12, mother and two children, remain about the same. The treatment has been almost continuous throughout the year. Because of positive complement fixation test for tuberculosis, it is possible we are dealing with a latent tuberculosis, which may account for the poor results.

Case 14, a young woman whose engagement was broken on account of the odor, has remained a remarkable clinical but not a bacteriologic cure. The girl married her former affianced and considers herself cured. 
Case. 21, Sister P., three years under treatment for pansinuitis, remains clinically but not bacteriologically cured. She has had no vaccine treatment for the past year.

Case 22, dentist, who was obliged to limit his practice on account of the odor, remains a permanent clinical cure. He has had one or two short vaccine treatments throughout the year, and still gives a positive B. rhinosepticus.

Thus it will be seen that every case in Chart II reported as clinical cures have remained so, a very satisfactory record. The constant presence of the B. rhinosepticus shows that these cures are not permanent, but that antibodies must be supplied indefinitely in the form of small doses of vaccines, repeated at intervals, for an indeterminate period.

Chart III contained nine cases, eight Friedlander ozena, treated with our vaccine. Seven of the nine noted as clinical cures did not return for further treatment. The other two have remained entirely well without vaccine or local treatment during the year. The Friedlander is still present in cultures.

Analysis of Results of New Cases Treated Since Last REPORT.-Twenty-six cases are reported in our new series (Table III). Six were untreated. Five did not improve. Six cases were improved as the results of operative drainage on the sinuses, and no credit was given to the vaccine. In the nine remaining cases great improvement or clinical cures are noted.

Of the five cases showing no improvement, only one was a true B. rhinosepticus ozena. This case received but three injections and did not return.

The remaining nine cases form a happy paragraph in the therapy of this disease. The improvement was marked, in some cases very striking, the crusts and odor rapidly disappeared. The frontal headaches invariably cleared up after the third or fourth injection. Weight and general condition improved. These and the last year's series have been carefully and fairly studied. We see no reason to change our conclusion of last year (No. 5), that "at present mixed vaccines made from various strains of the Perez-bacillus (B. rhinosepticus) is the most practical method of treatment which is now available." 


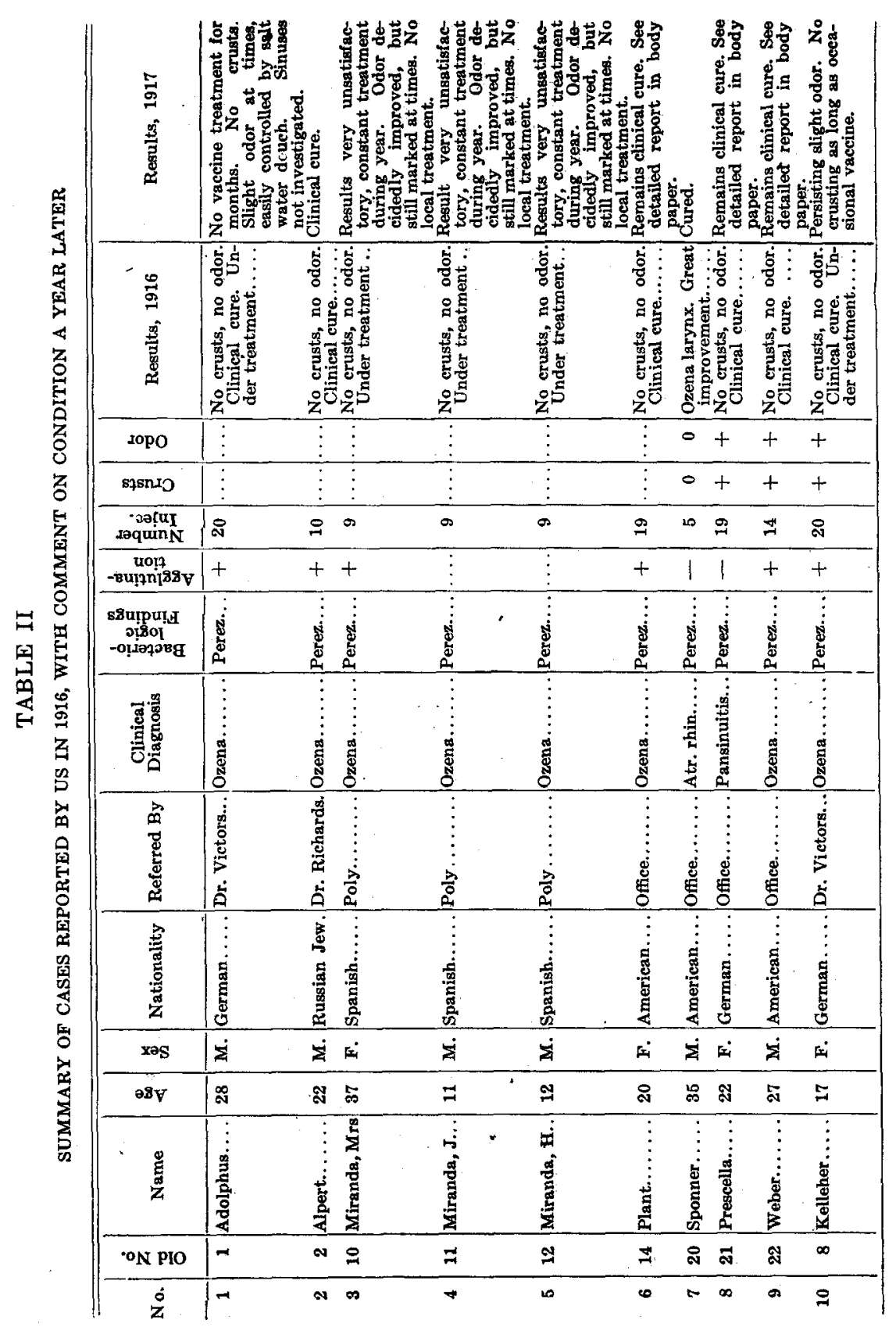




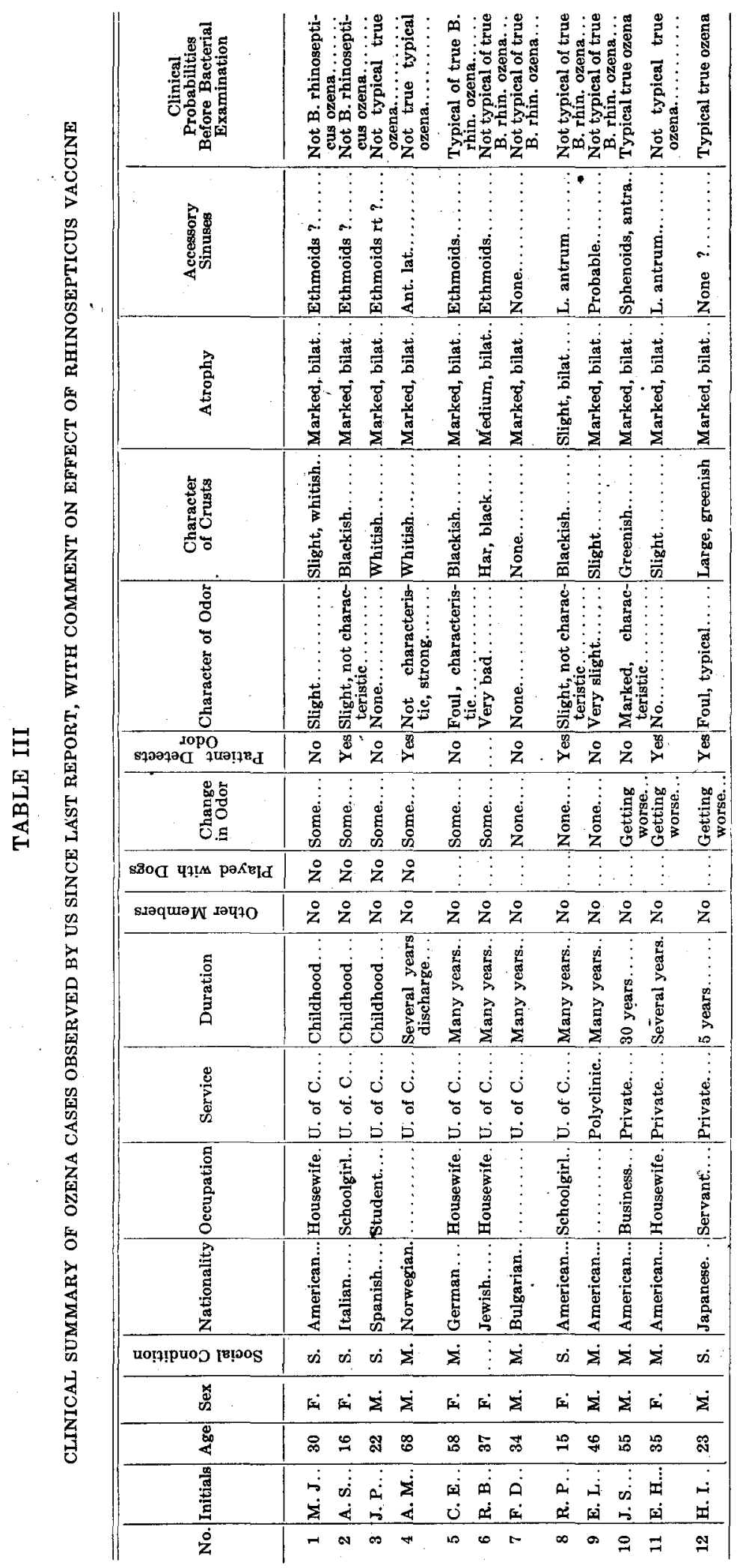




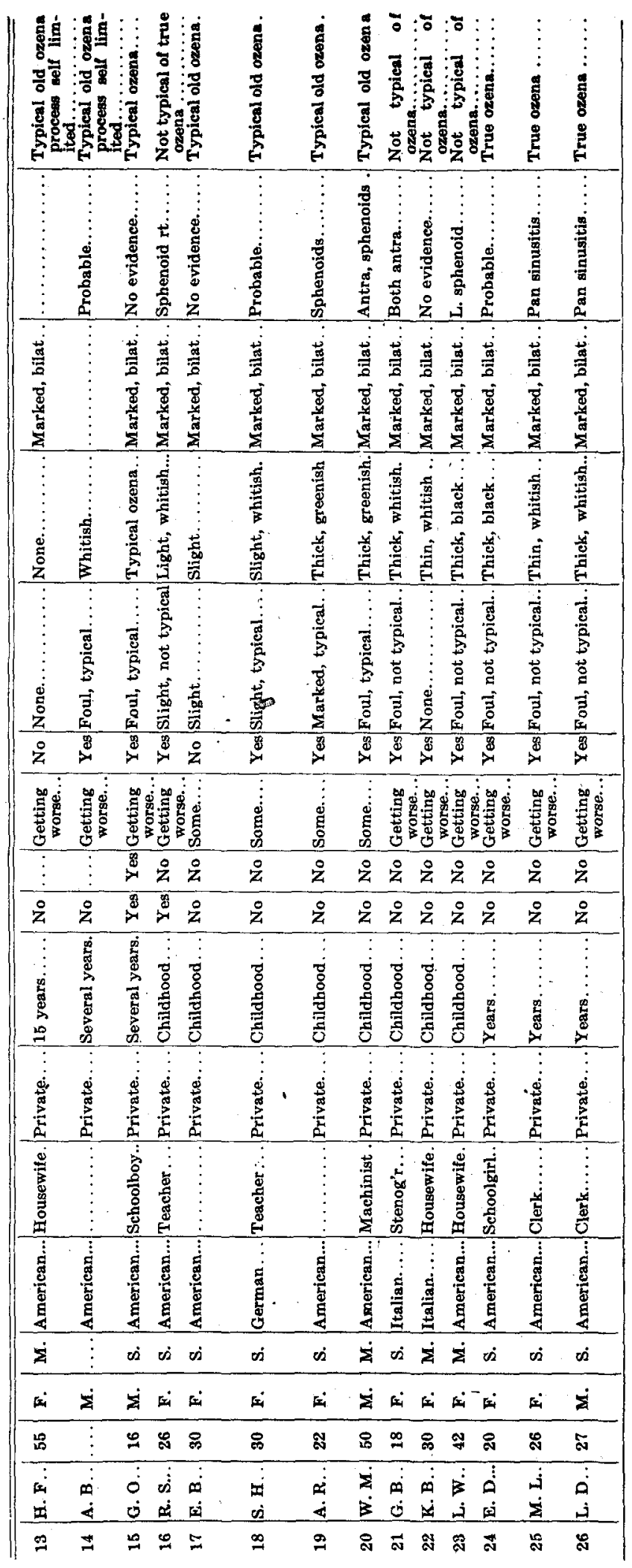




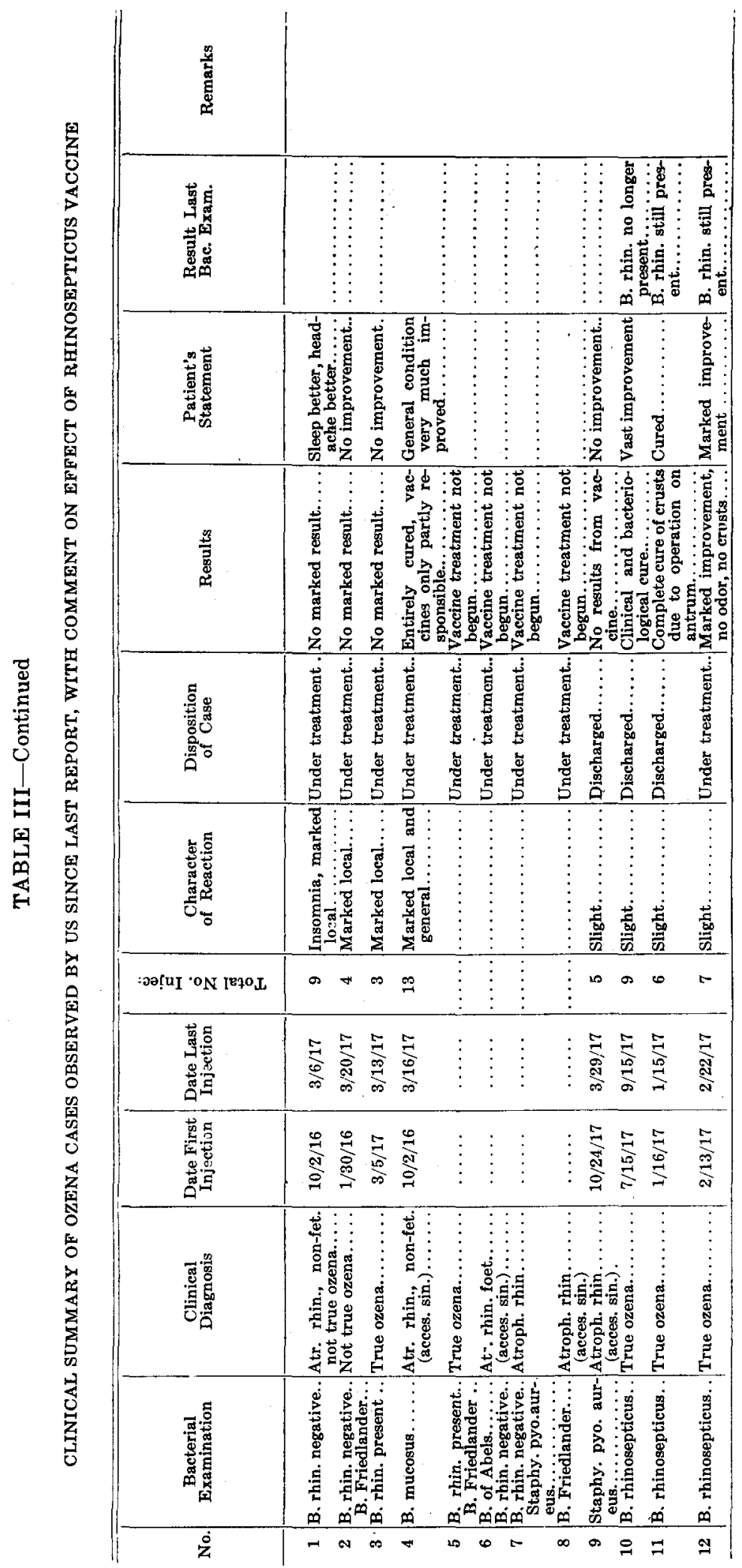




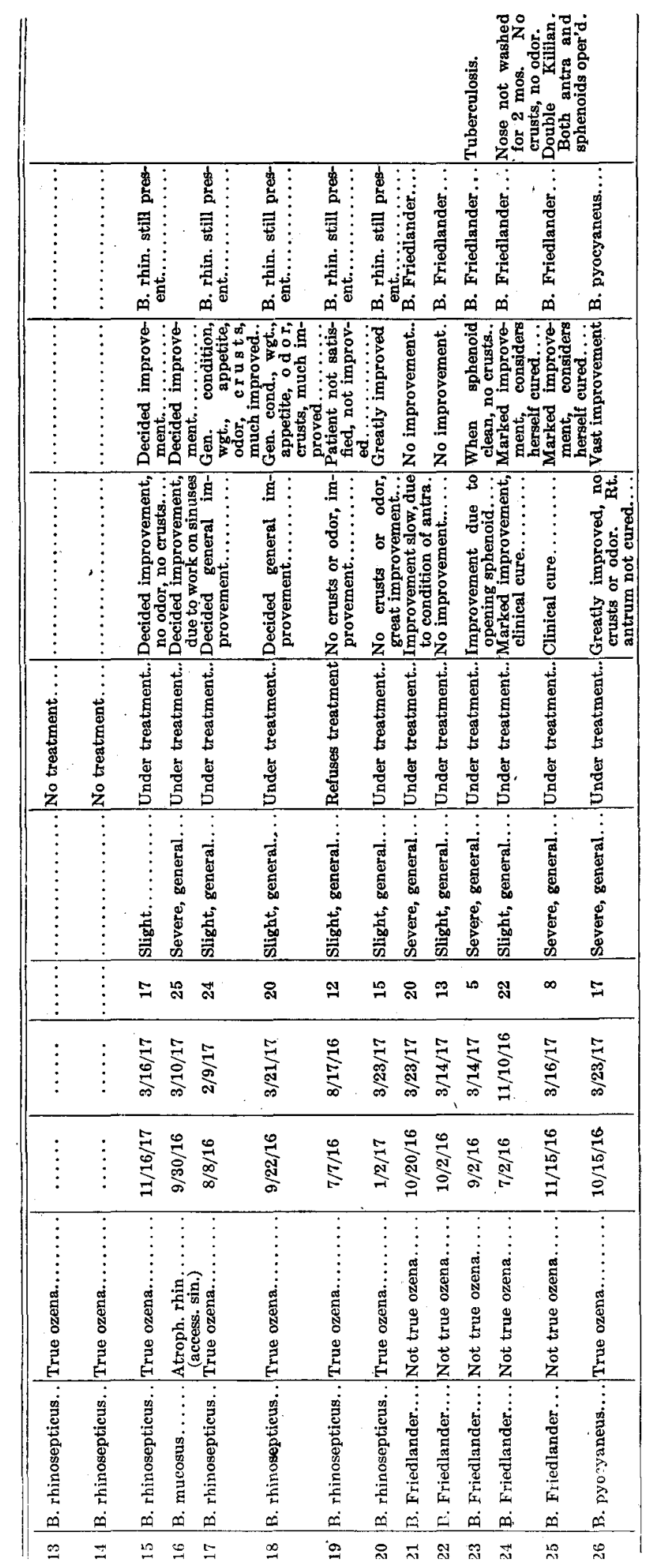




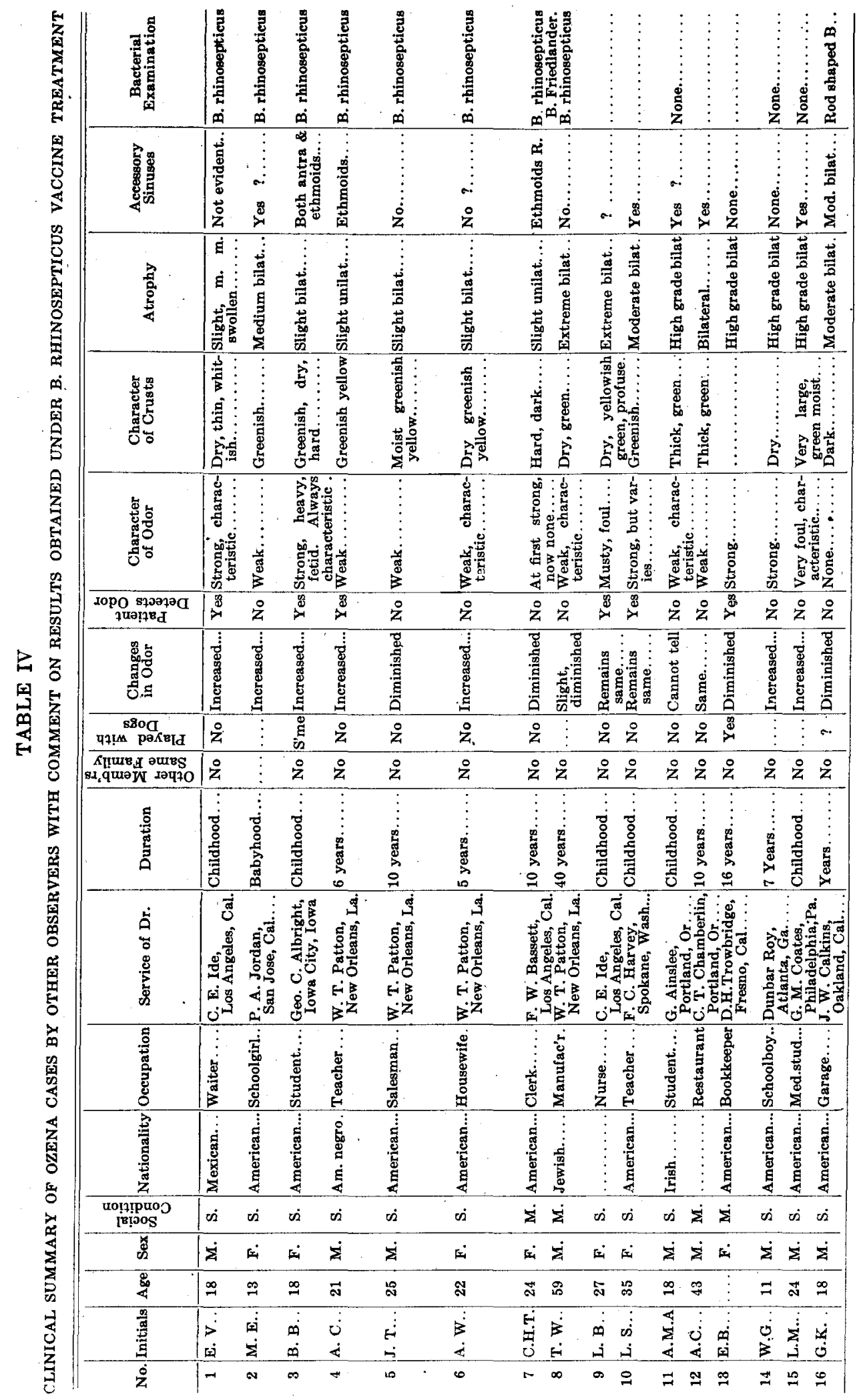




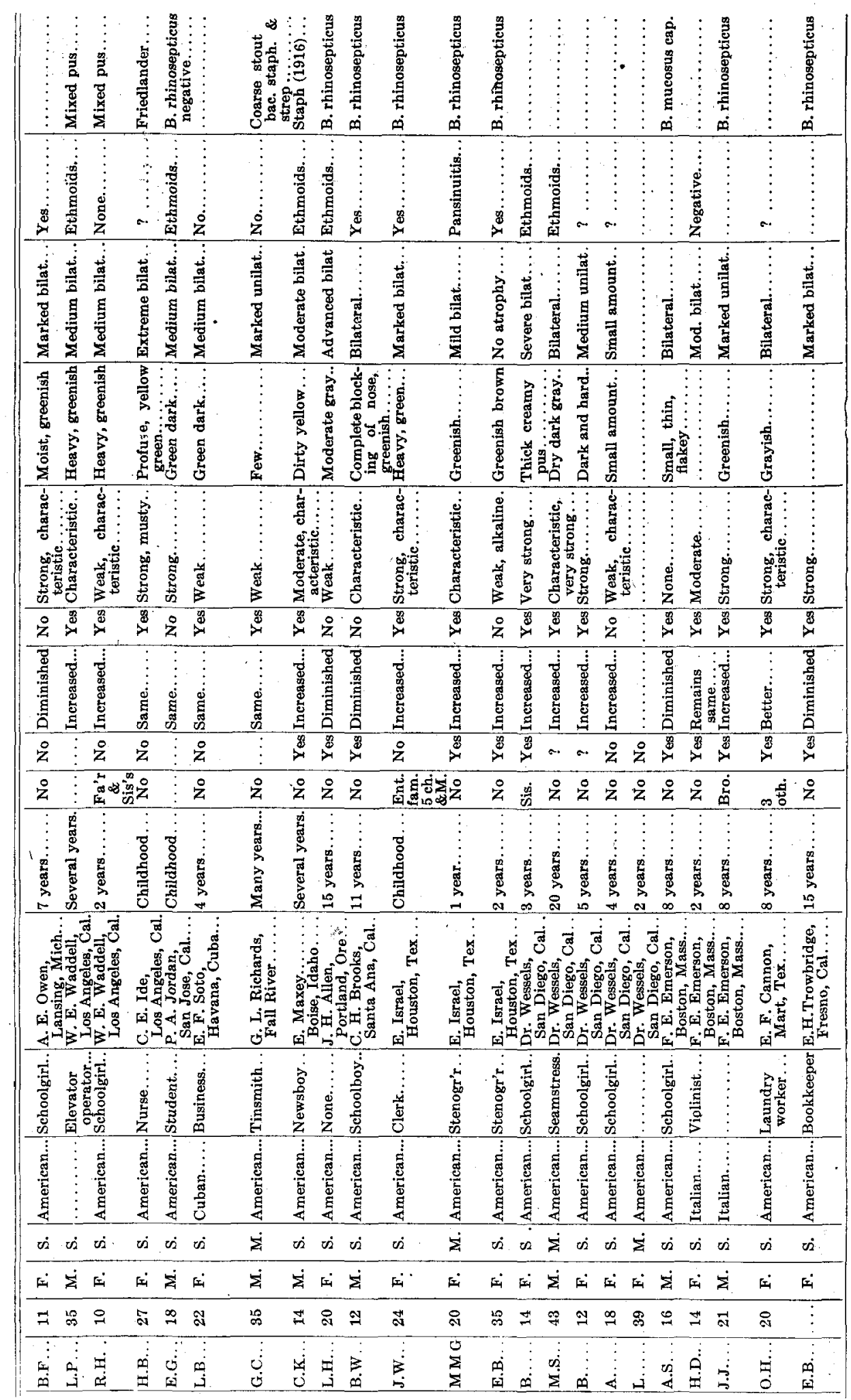




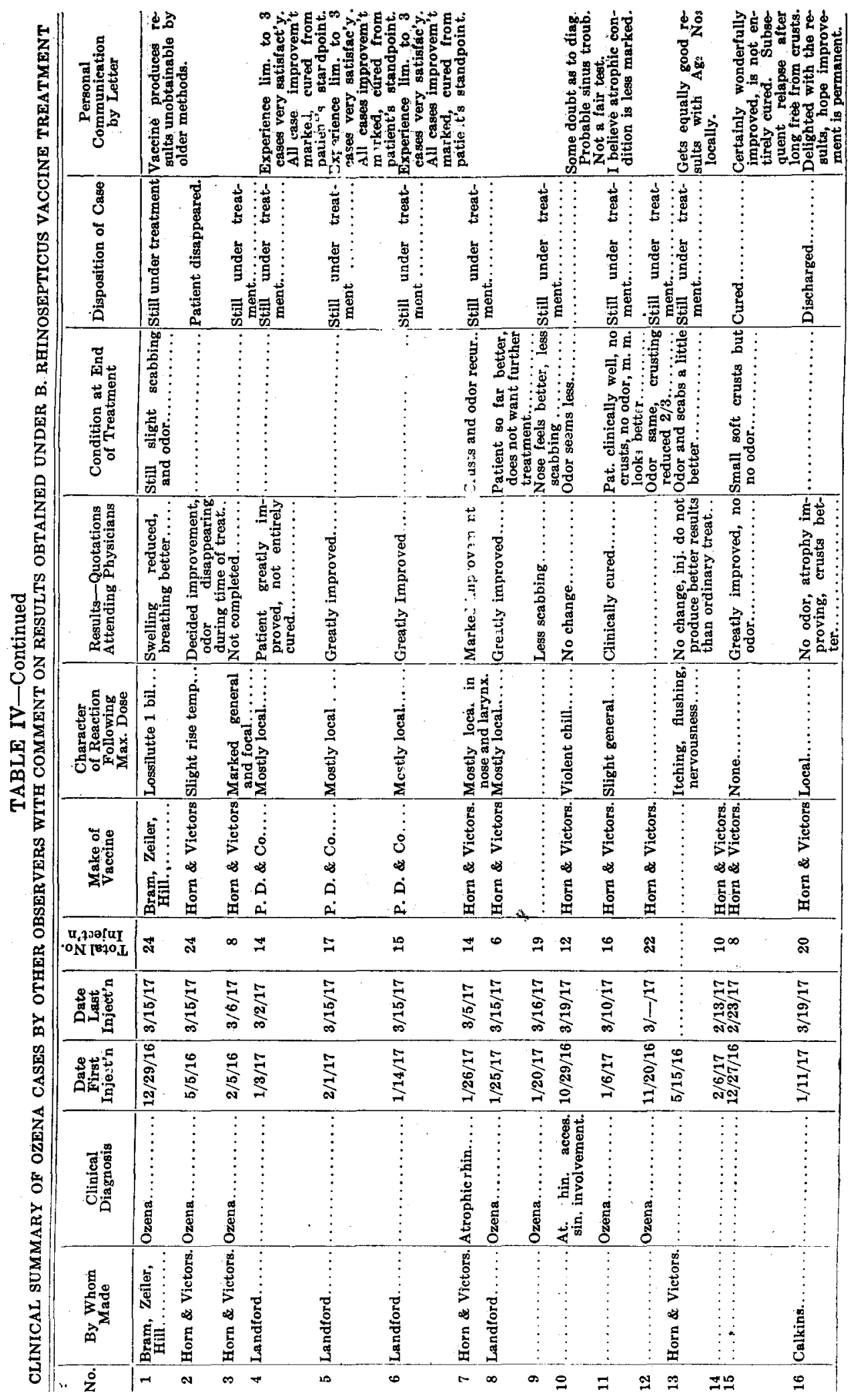




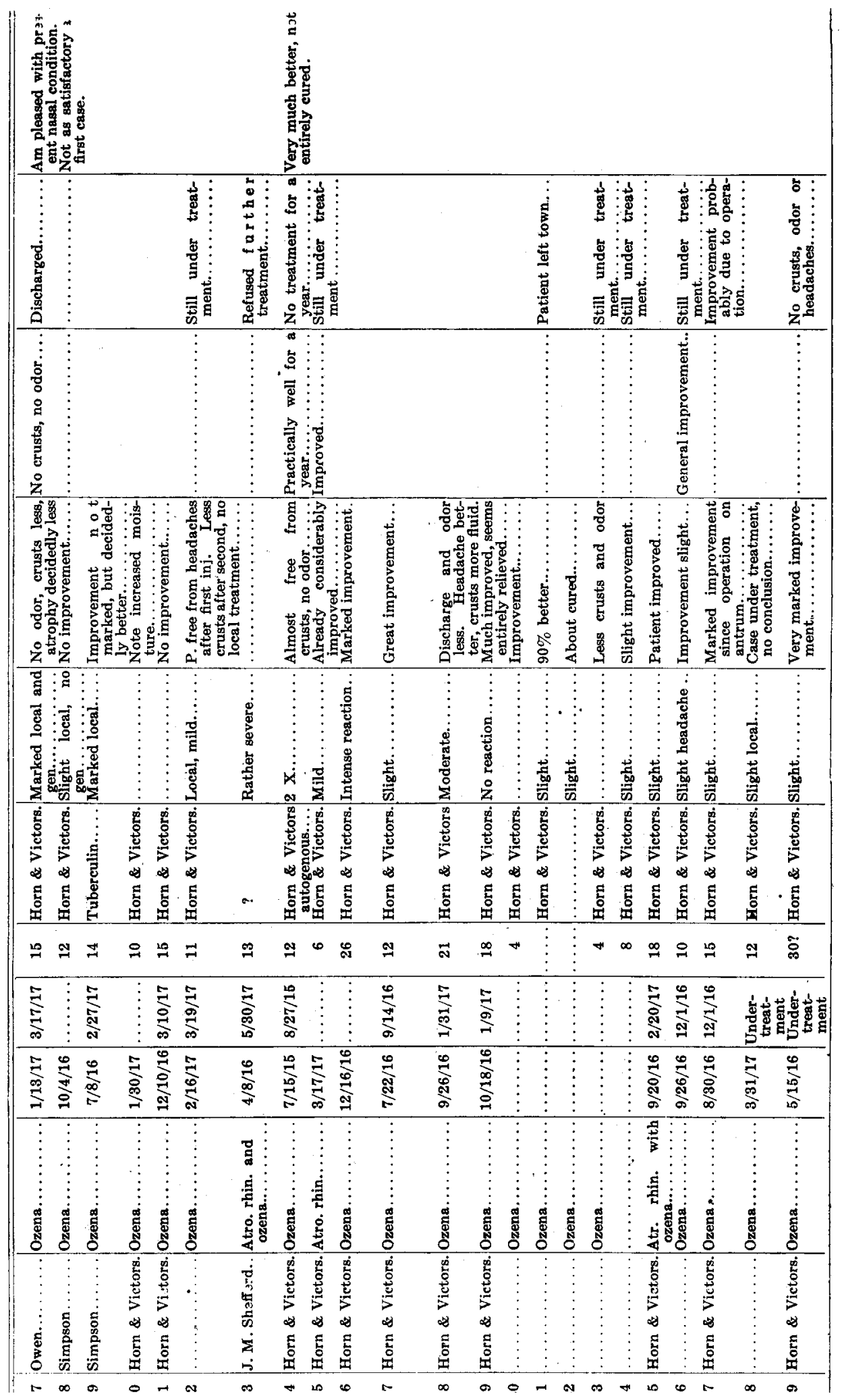

